\title{
Modelling the optical properties of fresh biomass burning aerosol produced in a smoke chamber: results from the EFEU campaign
}

\author{
K. Hungershoefer ${ }^{1,}{ }^{*}$, K. Zeromskiene ${ }^{2,4}$, Y. Iinuma ${ }^{2}$, G. Helas ${ }^{3}$, J. Trentmann ${ }^{5}$, T. Trautmann ${ }^{1,6}$, R. S. Parmar ${ }^{3,8}$, \\ A. Wiedensohler ${ }^{2}$, M. O. Andreae ${ }^{3}$, and O. Schmid ${ }^{3,7}$ \\ ${ }^{1}$ Institute for Meteorology, University of Leipzig, Leipzig, Germany \\ ${ }^{2}$ Leibniz-Institute for Tropospheric Research, Leipzig, Germany \\ ${ }^{3}$ Max Planck Institute for Chemistry, Biogeochemistry Dept., Mainz, Germany \\ ${ }^{4}$ Centre for Atmospheric Chemistry, York University, Toronto, Canada \\ ${ }^{5}$ Institute for Atmospheric Physics, Johannes Gutenberg University Mainz, Mainz, Germany \\ ${ }^{6}$ Remote Sensing Technology Institute, German Aerospace Centre, Wessling, Germany \\ ${ }^{7}$ Institute for Inhalation Biology, GSF-National Research Centre for Environment and Health, Neuherberg, Germany \\ ${ }^{8}$ IIMT Engineering College, Department of Applied Science, Ganga Nagar, Meerut, India \\ * now at: Laboratoire Inter-Universitaire des Systèmes Atmosphériques (LISA), Université Paris 7/12 and CNRS (UMR \\ 7583), Créteil, France
}

Received: 30 July 2007 - Published in Atmos. Chem. Phys. Discuss.: 29 August 2007

Revised: 7 May 2008 - Accepted: 27 May 2008 - Published: 2 July 2008

\begin{abstract}
A better characterisation of the optical properties of biomass burning aerosol as a function of the burning conditions is required in order to quantify their effects on climate and atmospheric chemistry. Controlled laboratory combustion experiments with different fuel types were carried out at the combustion facility of the Max Planck Institute for Chemistry (Mainz, Germany) as part of the "Impact of Vegetation Fires on the Composition and Circulation of the Atmosphere" (EFEU) project. The combustion conditions were monitored with concomitant $\mathrm{CO}_{2}$ and $\mathrm{CO}$ measurements. The mass scattering efficiencies of $8.9 \pm 0.2 \mathrm{~m}^{2} \mathrm{~g}^{-1}$ and $9.3 \pm 0.3 \mathrm{~m}^{2} \mathrm{~g}^{-1}$ obtained for aerosol particles from the combustion of savanna grass and an African hardwood (musasa), respectively, are larger than typically reported mainly due to differences in particle size distribution. The photoacoustically measured mass absorption efficiencies of $0.51 \pm 0.02 \mathrm{~m}^{2} \mathrm{~g}^{-1}$ and $0.50 \pm 0.02 \mathrm{~m}^{2} \mathrm{~g}^{-1}$ were at the lower end of the literature values. Using the measured size distributions as well as the mass scattering and absorption efficiencies, Mie calculations provided effective refractive indices of 1.60-0.010i (savanna grass) and 1.56-0.010i (musasa) $(\lambda=0.55 \mu \mathrm{m})$. The apparent discrepancy between the low imaginary part of the refractive index and the high apparent elemental carbon $\left(\mathrm{EC}_{\mathrm{a}}\right.$ ) fractions (8 to $\left.15 \%\right)$ obtained
\end{abstract}

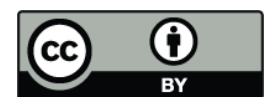

Correspondence to: K. Hungershoefer (hungershoefer@lisa.univ-paris12.fr) from the thermographic analysis of impactor samples can be explained by a positive bias in the elemental carbon data due to the presence of high molecular weight organic substances. Potential artefacts in optical properties due to instrument bias, non-natural burning conditions and unrealistic dilution history of the laboratory smoke cannot be ruled out and are also discussed in this study.

\section{Introduction}

Vegetation fires in the tropics, the mid-latitudes and boreal regions are a significant source of atmospheric trace gases and aerosol particles which affect the atmospheric chemistry and the radiation budget on a global scale (Crutzen and Andreae, 1990; Andreae, 1991; Penner et al., 1992). One of the difficulties in assessing the regional and global impact of biomass burning aerosol is the fact that the physico-chemical properties of biomass burning aerosol strongly depend on the fuel characteristics, combustion conditions and the age of the smoke (Andreae and Merlet, 2001).

In the last decades, a number of biomass burning field experiments have taken place in various ecosystems throughout the world, such as the South African Fire-Atmosphere Research Initiatives (SAFARI) (Lindesay et al., 1996; Swap et al., 2002), the Smoke, Clouds, and Radiation - Brazil (SCAR-B) (Kaufman et al., 1998), and the Smoke Aerosols,

Published by Copernicus Publications on behalf of the European Geosciences Union. 


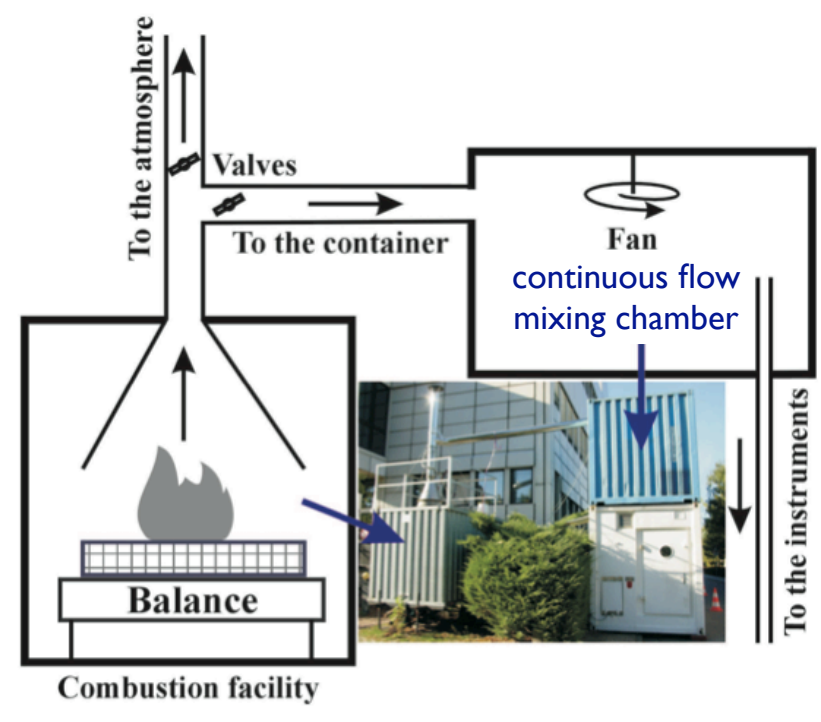

Fig. 1. Experimental setup at the Max Planck Institute for Chemistry in Mainz during the EFEU campaigns. On the left hand side of the photograph the combustion facility that contains the oven is seen. The blue buffer container is shown on the right on top of a white field laboratory container, that comprises part of the instruments.

Clouds, Rainfall and Climate (SMOCC) campaigns in South America. Whereas the results from such field experiments always reflect a mixture of fuels and burning conditions, laboratory experiments provide the possibility of a fuel specific characterisation of biomass emissions under controlled combustion conditions. Previous laboratory experiments dealt with the absorption properties of forest fire aerosol (Patterson and McMahon, 1984; Patterson et al., 1986), the characterisation of organic compounds (e.g., Simoneit, 2002), and emission characteristics (Christian et al., 2003). The current state of knowledge of biomass burning emissions from both field and lab experiments as well as satellite measurements, is presented in the review papers by Koppmann et al. (2005) and Reid et al. (2005a,b).

The optical properties of combustion aerosol strongly depend on particle size, shape and black carbon (BC) content and thus on fuel type and combustion conditions. Hence, the relatively wide range of optical properties for biomass burning particles reported in the literature reflects the dynamic nature of vegetation fires, variations in smoke ageing processes and - to some degree - differences in measurement techniques (Reid et al., 2005a). Consequently fundamental parameters such as the complex refractive index of the particles as well as their major constituents, namely black (or elemental) and organic carbon (OC), are highly uncertain and have to be further investigated in order to deduce the uncertainty in global estimates of direct forcing (Reid et al., 2005a).

One possibility for an improved, more thorough characterisation of particles from biomass combustion arises from per- forming combustion experiments in the lab. Recently, Chen et al. (2006) and Chakrabarty et al. (2006) conducted such experiments with fuels commonly burned in mid-latitude forests. Laboratory combustion experiments were also carried out as part of the "Impact of Vegetation Fires on the Composition and Circulation of the Atmosphere" (EFEU) project (Wurzler et al., 2001). In addition to fuels from the boreal forest region, African savanna and peat samples were investigated in the EFEU project.

The present study deals with the aerosol optical properties (scattering and absorption) obtained from the combustion of African savanna grass and musasa (an African hardwood) during EFEU. The measured optical properties are compared with results from previous field and lab experiments and possible reasons for the observed differences are discussed based on model calculations using Mie theory.

\section{Methodology}

In 2003 a series of controlled combustion experiments with various types of biomass were carried out at the combustion facility of the Max Planck Institute for Chemistry in Mainz, Germany, as part of the EFEU project. The experimental setup is shown in Fig. 1. In brief, it consists of a laboratory oven with a $60 \mathrm{~cm} \times 60 \mathrm{~cm}$ burning table placed on a highresolution balance to determine the combusted fuel mass and derive the mass emission factors. The combustion emissions were drawn at a flow rate of about $3.6 \mathrm{~m}^{3} \mathrm{~min}^{-1}$ into a $32.6 \mathrm{~m}^{3}$ metal container, which was operated as continuous flow mixing chamber with active mixing (internal fan) in order to reduce the temporal variability of the samples. Sampling was performed from the mixing chamber and most aerosol instruments were located in a container directly below the mixing chamber and operated with a 1:20 dilution to avoid instrument saturation.

The main goal of the experiments was the characterisation of the physical and chemical properties of the generated smoke particles. In total, 26 combustion experiments were performed during two measurement periods in summer and autumn 2003. The reproducibility of the results was confirmed by repeating several experiments with the same fuel. In all cases the fuel moisture was very low (approximately $10 \%$ ) and the size of the wood logs was relative small (thin branches, $20-40 \mathrm{~cm}$ long).

A typical burn for a given fuel lasted about one hour and during this time new fuel material was added to the fire to maintain stable burning conditions and to guarantee a continuous flow of fresh smoke into the continuous flow mixing chamber. The average residence time of the particles in the container was about 8 min.

The smoke particles were characterised with respect to a wide range of aerosol parameters including size distribution, morphology, chemical composition, mass and optical properties. The combustion conditions were monitored with 
concomitant $\mathrm{CO}_{2}$ and $\mathrm{CO}$ measurements. Using Mie calculations and some simplifying assumptions, these data were used to derive the refractive index of both the light absorbing fraction and organic matter. Here we concentrate on two EFEU experiments, namely the combustion of savanna grass (Poaceae: Heteropogon spec.) from Etosha, Namibia, and the combustion of musasa (Brachystegia spiciformis, sometimes also called msasa), hardwood from Zimbabwe. During the combustion of the savanna grass, a few acacia twigs (Acacia spec.) were added to maintain a reasonably steady combustion process. The two African fuels were chosen, because (1) not all of the experiments provided data on all of the parameters needed for the analysis presented here, (2) tropical Africa contains about two thirds of the savanna regions worldwide, and (3) savanna fires are the largest source of biomass burning regarding the amount of burned biomass (Hao and Liu, 1994; Andreae et al., 1996).

\subsection{Measurements}

Gas phase measurements of carbon monoxide $(\mathrm{CO})$ and carbon dioxide $\left(\mathrm{CO}_{2}\right)$ were performed directly from the mixing chamber with a non-dispersive infrared analyser (NDIR) to monitor the combustion conditions. Aerosol measurements were also performed from the mixing chamber, but with a 1:20 dilution stage except for the real-time mass measurement, which was performed with a Tapered Element Oscillating Microbalance (TEOM 1400a, Thermo Scientific, NY) from a separate inlet with a 1:10 dilution stage. The TEOM was operated at a temperature of $30^{\circ} \mathrm{C}$ in order to minimize mass loss due to volatilization of semi-volatile aerosol compounds. The number size distribution was measured with a Scanning Mobility Particle Sizer (SMPS) and an Aerodynamic Particle Sizer (APS, TSI 3321, TSI Inc., MN) for particle diameters between $0.012-0.81 \mu \mathrm{m}$ and $0.5-10 \mu \mathrm{m}$, respectively. To merge the SMPS and APS measurements, the SMPS data was used up to $0.81 \mu \mathrm{m}$ and extended to larger diameters by the APS measurements without any adjustment. This is justified by the fact that no significant shift was observed between both size distributions indicating effective particle densities near unity (Schmid et al., 2007). The total particle concentration was monitored with a condensation particle counter (CPC, TSI 3022A, TSI Inc., MN). A Berner type impactor with five size bins $(0.05-0.14,0.14-0.42$, $0.42-1.2,1.2-3.5,3.5-10 \mu \mathrm{m}$ diameter) was employed to determine size-resolved particle mass using a microbalance (Mettler Toledo, OH). Additionally, a thermographic method was applied to these impactors to determine the organic carbon $(\mathrm{OC})$ and apparent elemental carbon $\left(\mathrm{EC}_{\mathrm{a}}\right)$ mass fraction using a C-mat 5500 instrument (Stroehlein, Germany), where $\mathrm{OC}$ and $\mathrm{EC}_{\mathrm{a}}$ are defined as follows: $\mathrm{OC}$ is the $\mathrm{CO}_{2}$ fraction evolving under nitrogen at $650^{\circ} \mathrm{C}$ with $\mathrm{CuO}$ as a catalytic reagent and $\mathrm{EC}_{\mathrm{a}}$ is the evolving $\mathrm{CO}_{2}$ fraction under oxygen at $650^{\circ} \mathrm{C}$. The term "apparent elemental carbon" is used in this study, because this species is operationally defined and does not correspond to a rigorously definable chemical species (Andreae and Gelencsér, 2006). A detailed discussion of the $\mathrm{OC} / \mathrm{EC}_{\mathrm{a}}$ method used here and artefacts due to higher molecular weight organic compounds on $\mathrm{OC}-\mathrm{EC}_{\mathrm{a}}$ separation is presented in Iinuma et al. (2007). A comprehensive comparison of this method with other $\mathrm{OC} / \mathrm{EC}_{\mathrm{a}}$ methods can be found elsewhere (Schmid et al., 2001). An integrating nephelometer (TSI 3563, TSI Inc., MN) was employed for measurements of the scattering coefficient at three wavelengths in the visible spectral range $(\lambda=0.45,0.55$ and $0.7 \mu \mathrm{m})$ and the data were corrected for the effect of angular non-idealities using Mie theory and the measured size distribution. The general uncertainties of an integrating nephelometer are discussed in Anderson and Ogren (1998). During the EFEU experiments, the reliability of the instrument was confirmed with $\mathrm{CO}_{2}$ as calibration gas. The absorption coefficient was determined with a photoacoustic spectrometer (PAS) at $\lambda=0.532 \mu \mathrm{m}$ and a particle soot absorption photometer (PSAP, Radiance Research, WA) at $\lambda=0.565 \mu \mathrm{m}$. Measurements with both instruments agreed within the range of experimental uncertainty, but we will use the PAS data here, since it is less prone to measurement artefacts than filter-based instruments such as the PSAP (Schmid et al., 2006). Mass scattering and absorption efficiencies were derived by dividing the scattering coefficients obtained from the nephelometer and the absorption coefficient from the PAS measurements by the mass concentrations obtained from the TEOM. Values of the single scattering albedo at $\lambda=0.55 \mu \mathrm{m}$ were calculated from the measured scattering coefficient at $\lambda=0.55 \mu \mathrm{m}$ and the PAS data, neglecting the small wavelength difference of the absorption coefficient. A humidified tandem differential mobility analyser (H-TDMA) was employed to determine the hygroscopic properties of the particles at initial dry diameters of $0.05,0.1$, $0.15,0.25,0.325$ and $0.450 \mu \mathrm{m}$ and a relative humidity of $85 \%$ (Massling et al., 2003).

To match the two minute measurement intervals of the SMPS, all measurements were averaged over the same time period except for the size-resolved $\mathrm{EC}_{\mathrm{a}}$ fractions from the chemical analysis, which were only available as averages over the whole duration of each continuous flow mixing experiment.

2.2 Modelling of the optical properties and derivation of refractive indices

The measured particle size distribution and the measured scattering and absorption coefficients were used to derive an effective refractive index from Mie theory. This was accomplished by iteratively adjusting the effective complex refractive index until the calculated scattering and absorption coefficients best matched the measured ones. In a second step, we assume that the model particles are composed of nonabsorbing organic carbon (with an imaginary part of the refractive index equal to zero) and strongly absorbing black carbon only (having 1.75 as real part of the refractive index) 
Table 1. Temporal averages of several parameters retrieved for the EFEU combustion experiments with savanna grass (SAVA20a) and musasa (MUSA23a) based on 30 (SAVA20a) and 29 (MUSA23a) data points. For the number size distribution the number fraction, count median diameter (CMD) and the geometric standard deviation $\left(\sigma_{g}\right)$ are given, assuming a three-modal lognormal distribution. In case of the optical properties the standard deviation of the mean is also given. More details on the mass emission factors can be found in Iinuma et al. (2007).

\begin{tabular}{lll}
\hline Quantity & SAVA20a & MUSA23a \\
\hline$\Delta \mathrm{CO} / \Delta \mathrm{CO}_{2}(\%)$ & $6.4 \pm 0.1$ & $9.0 \pm 0.3$ \\
$\mathrm{EC} \mathrm{a}$ mass fraction (\%) & 15.5 & 8.6 \\
$\mathrm{CPC}$ total number concentration $\left(10^{6} \mathrm{~cm}^{-3}\right)$ & $3.5 \pm 0.1$ & $4.3 \pm 0.1$ \\
number size distribtuion $($ lognormal $)$ & & \\
$\quad$ number fraction, Mode $1 / 2 / 3$ & $0.002 / 0.99791 / 0.00009$ & $0.006 / 0.99395 / 0.00005$ \\
$\quad \mathrm{CMD}_{1} / \mathrm{CMD}_{2} / \mathrm{CMD}_{3}(\mu \mathrm{m})$ & $0.01 / 0.134 / 2.0$ & $0.03 / 0.15 / 2.0$ \\
$\quad \sigma_{g, 1} / \sigma_{g, 2} / \sigma_{g, 3}$ & $1.50 / 1.87 / 1.55$ & $1.65 / 1.77 / 1.55$ \\
Ångstrom exponent $(0.45-0.55 \mu \mathrm{m})$ & $1.2 \pm 0.1$ & $1.1 \pm 0.1$ \\
Ångstrom exponent $(0.55-0.70 \mu \mathrm{m})$ & $1.8 \pm 0.1$ & $2.1 \pm 0.1$ \\
TEOM mass concentration $\left(\mathrm{mg} \mathrm{m}^{-3}\right)$ & $23.8 \pm 1.4$ & $27.4 \pm 1.0$ \\
Scattering coefficient $\left(\mathrm{m}^{-1}\right), \lambda=0.55 \mu \mathrm{m}$ & $0.21 \pm 0.01$ & $0.26 \pm 0.01$ \\
Mass scattering efficiency $\left(\mathrm{m}^{2} \mathrm{~g}^{-1}\right), \lambda=0.55 \mu \mathrm{m}$ & $8.9 \pm 0.2$ & $9.3 \pm 0.3$ \\
Absorption coefficient $\left(\mathrm{m}^{-1}\right), \lambda=0.532 \mu \mathrm{m}$ & $0.012 \pm 0.001$ & $0.014 \pm 0.001$ \\
Mass absorption efficiency $\left(\mathrm{m}^{2} \mathrm{~g}^{-1}\right), \lambda=0.532 \mu \mathrm{m}$ & $0.51 \pm 0.02$ & $0.50 \pm 0.02$ \\
Single scattering albedo, $\lambda=0.55 \mu \mathrm{m}$ & $0.945 \pm 0.004$ & $0.950 \pm 0.02$ \\
Mass emission factor $\left(\mathrm{g} \mathrm{kg}^{-1}\right)$ & 4.0 & 5.6 \\
Hygroscopic diameter growth factor $(\mathrm{RH}=85 \%)$ & $<1.3$ & $<1.1$ \\
\hline
\end{tabular}

(Lenoble, 1991; Penner et al., 1998; Reid and Hobbs, 1998; Haywood et al., 2003). This allows us to derive the real part of the OC refractive index as well as the imaginary part of the $\mathrm{BC}$ fraction using the $\mathrm{EC}_{\mathrm{a}}$ mass fraction (thermographic method) as proxy for the $\mathrm{BC}$ volume fraction. Thereby, the effective refractive index of the internal OC-BC mixture was determined with the mixing rule of Maxwell-Garnett (MG) (Maxwell Garnett, 1904), which is preferable to simple volume mixing for particles composed of non or slightly absorbing matter containing a small amount of spherical, stronglyabsorbing inclusions (Chýlek et al., 1988). Alternatively, stratified spheres with particles composed of a BC core and a shell of organic carbon assuming a constant ratio of core diameter to particle diameter were used. The chemical composition was presumed to be the same for all sizes and constant over the whole duration of the experiment, because no time-resolved chemical composition measurements were performed and differences in size-resolved chemical composition are irrelevant for our analysis as discussed below. Hence, for a given experiment temporal changes in the modelled optical properties are solely due to changes in the particle size distribution, not due to variations in the chemical composition. This allows an exploration of whether the observed changes in scattering/absorption are due to changes in particle size or chemistry.

The hygroscopic growth of the particles did not have to be considered in the model calculations, because the particles were dried to approximately $10 \%$ relative humidity by passing through the dilution system. The assumptions of particle sphericity (here: compact particle shape) and internally mixed particles were justified by scanning electron microscopy (not shown). In addition, Schneider et al. (2006) found dynamic shape factors of less than 1.2 for similar burns, which also indicates compact particle shape. An estimate of a potential bias due to non-spherical particle shape will be given below. To convert the calculated optical properties into mass specific optical properties of the model particles, the experimentally determined (effective) particle density (obtained from the ratio of the TEOM mass concentration and the SMPS-APS volume concentration) was used. This ensures that the modelled aerosol mass concentration agrees with the TEOM mass data.

\section{Results}

\subsection{Experimental results}

During the SAVA20a experiment, $580 \mathrm{~g}$ of savanna grass and $716 \mathrm{~g}$ of acacia were burnt, where the latter was only used to ignite and maintain a sufficiently stable burning process. The largest amount of the acacia was combusted in the initial stage of the experiment (ignition at 11:15; emission into the container starting at 11:17) and the video recording showed that it was nearly completely burnt before 11:29 when the measurements started. Hence, we consider experiment SAVA20a to be representative for savanna grass. The temporal development of the fire can be summarised 

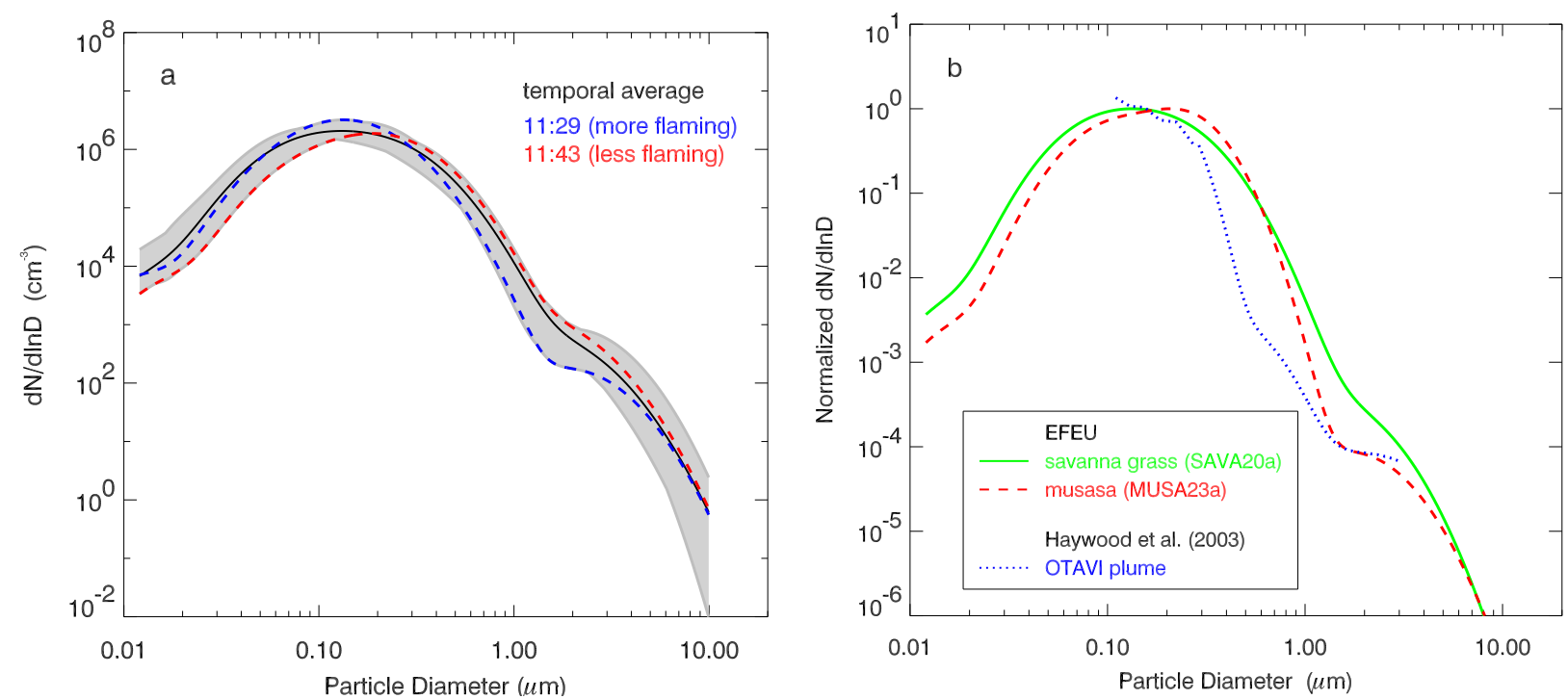

Fig. 2. (a) Range in the number size distribution during the SAVA20a experiment (gray area). Additionally, the temporal average (black line) and the size distributions at 11:29 and 11:43 are given. (b) Average number size distribution measured during the EFEU combustion experiments with savanna grass (SAVA20a) and musasa (MUSA23a). For comparison, the size distribution of fresh biomass burning aerosol (less than one minute old) sampled during the Southern African Regional Science Initiative (SAFARI2000) in a plume over a biomass burning fire near Otavi, Northern Namibia (Haywood et al., 2003) is also shown. All size distributions were normalized to their peak concentration to facilitate visual data comparison.

as follows: Each time after a handful of dry grass was put into the fire, large flames appeared, but decreased within 20 to $40 \mathrm{~s}$ and then some new grass was added. Occasionally some small acacia pieces were also put into the fire to sustain the combustion. Hence, for most of the time this experiment was characterised by a rapid change between flaming and smouldering burning conditions - resulting in a mixed phase combustion for each of the two-minutes averaging intervals. During the MUSA23a experiment $948 \mathrm{~g}$ of musasa (pieces of a medium sized branches) was burnt. The video recording showed small flames for most of the experiment except after occasional rearrangement of the fuel, which produced moderate flames. After a period of a few minutes the flames decreased and more smoke was visible so that again the experiment was dominated by mixed phase combustion.

For each experiment, the averaged aerosol number size distributions were fitted with a tri-modal lognormal distribution as given in Table 1. Both EFEU combustion experiments show a dominating ( $>99 \%$ of particle number) and broad accumulation mode with a count medium diameter of $0.134 \mu \mathrm{m}$ (SAVA20a) and $0.15 \mu \mathrm{m}$ (MUSA23a) and a geometric standard deviation of 1.87 (SAVA20A) and 1.77 (MUSA23a), respectively (Table 1). A clear coarse mode at $2 \mu \mathrm{m}$ is also seen (Fig. 2). The coarse particles seem to be emitted directly from the fire, because they already appear at the very beginning of the experiment and coagulation among accumulation mode particles is slow and does not transfer particles to the coarse mode. Although no attempts were made to remove dust or dirt from the fuel prior to combustion, we consider the coarse mode particles to be unburned parts of biomass (char), since the carbon content of the coarse mode particles was similar to the fine mode particles (Iinuma et al., 2007). For comparison, the size distribution of fresh biomass burning aerosol (less than one minute old) sampled during the Southern African Regional Science Initiative (SAFARI2000) in a plume over a biomass burning fire near Otavi (Northern Namibia) is also shown in Fig. 2b (Haywood et al., 2003). The distributions were normalised to their peak values to facilitate visual comparison. The Otavi fire consisted of both flaming and smouldering combustion and the area is close to Etosha, the origin of the savanna grass that was used for the EFEU experiment. The tri-modal Otavi size distribution is similar to the EFEU data, showing an accumulation and coarse mode at diameters of 0.2 and $2 \mu \mathrm{m}$, respectively, with relative contributions to the total particle concentration that are comparable to the EFEU data. However, in contrast to our results, the coarse mode is likely to contain a significant amount of dust (Haywood et al., 2003). In case of SAVA20a and MUSA23a there is an elevated abundance of large accumulation mode particles $(D>0.2 \mu \mathrm{m})$ compared to the Otavi measurements which is possibly due to reduced coagulation in the Otavi data as result of plume dilution. The smaller scattering Ångstrom exponents for the EFEU experiments (1.2 (SAVA20a) and 1.1 (MUSA23a)) in the spectral range between $\lambda=0.45 \mu \mathrm{m}$ and $\lambda=0.55 \mu \mathrm{m})$ compared to typical values for fresh smoke (2.0-2.5, Reid et al. (2005b)) confirm the higher fraction of large particles. 

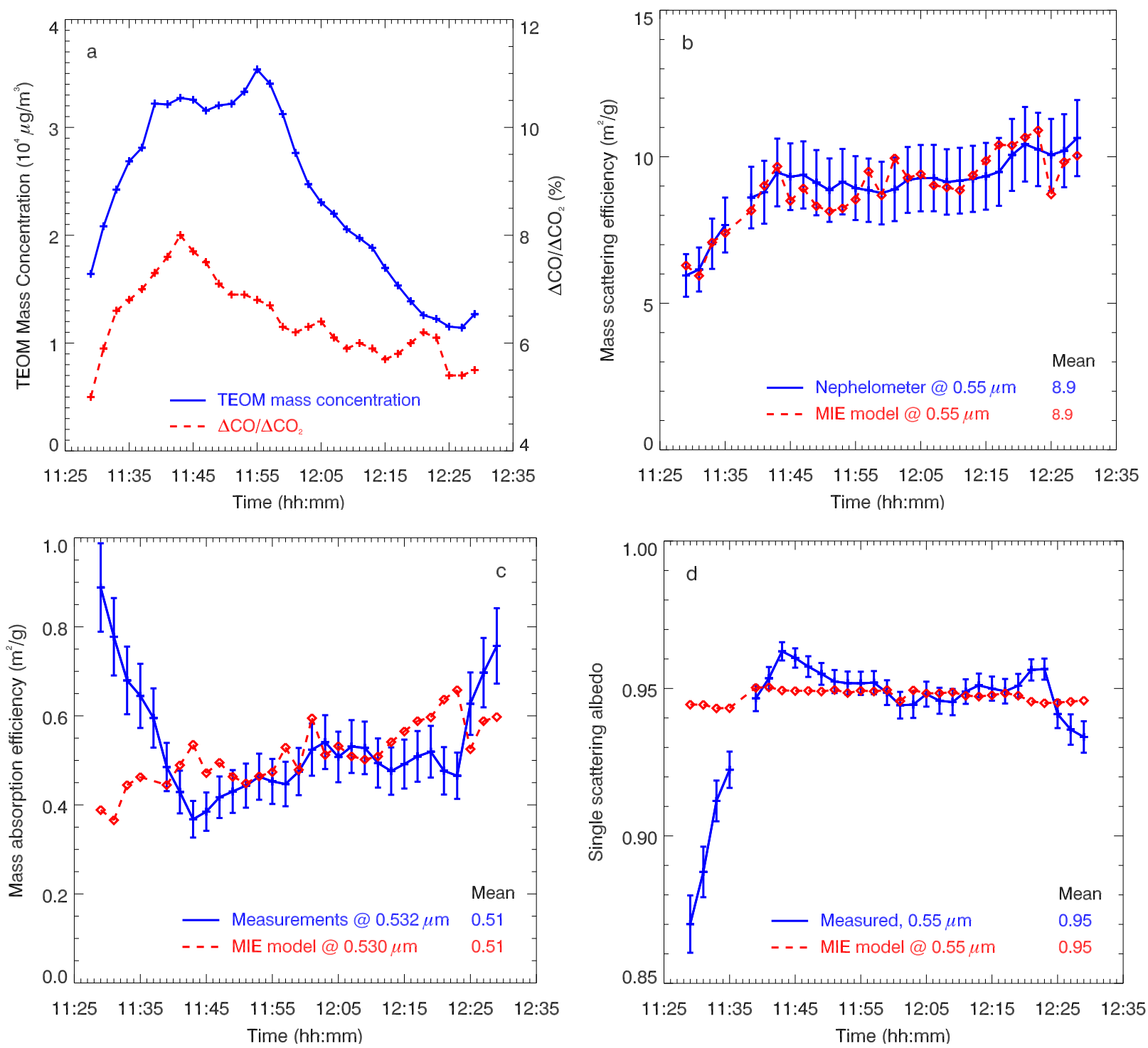

Fig. 3. Temporal development of various parameters during the combustion of savanna grass (SAVA20a): (a) TEOM mass concentration (left y-axis) and $\mathrm{CO}$ emission ratio $\left(\Delta \mathrm{CO} / \Delta \mathrm{CO}_{2}\right)$ (right y-axis), (b) mass scattering efficiency, (c) mass absorption efficiency, and (d) single scattering albedo. For the mass concentration measured with the TEOM a $10 \%$ inaccuracy is expected. For the single scattering albedo and the mass scattering and absorption efficiency the uncertainty was calculated with the Gauss error law, assuming an uncertainty of the nephelometer and the photoacoustic spectrometer of $7 \%$ and $5 \%$, respectively.

The burning conditions during the course of the EFEU combustion experiments are described by the $\mathrm{CO}$ emission ratio, $\Delta \mathrm{CO} / \Delta \mathrm{CO}_{2}$, where $\Delta \mathrm{CO}$ and $\Delta \mathrm{CO}_{2}$ are the carbon monoxide $(\mathrm{CO})$ and the carbon dioxide $\left(\mathrm{CO}_{2}\right)$ concentrations above the background level. Whereas low $\mathrm{CO}$ emission ratios (below approximately 11\%) indicate a more complete (i.e. flaming) combustion, higher values (above approximately $11 \%$ ) are typical for a less complete (smouldering) combustion (Reid et al., 2005b). In case of SAVA20a and MUSA23a the mean $\triangle \mathrm{CO} / \Delta \mathrm{CO}_{2}$ values were $(6.4 \pm 0.1) \%$ and $(9.0 \pm 0.3) \%$, respectively (Table 1$)$, indicating that the flaming phase was dominating. The particle mass emission factors were 4.0 and $5.6 \mathrm{~g} \mathrm{~kg}^{-1}$ for the SAVA20a and MUSA23a experiment, respectively (Table 1) and thus in a range similar to previously reported literature values (Iinuma et al., 2007). From the chemical analysis, averaged $\mathrm{EC}_{\mathrm{a}}$ mass fractions of $15.5 \%$ (SAVA20a) and $8.6 \%$ (MUSA23a) were retrieved, i.e. higher $\mathrm{CO}$ emission ratios correspond to lower $\mathrm{EC}_{\mathrm{a}}$ fractions. This is in agreement with results from the other EFEU experiments (linuma et al., 2007) and with field experiments (Ferek et al., 1998). Particle diameter hygroscopic growth factors at a relative humidity $(\mathrm{RH})$ of $85 \%$ 

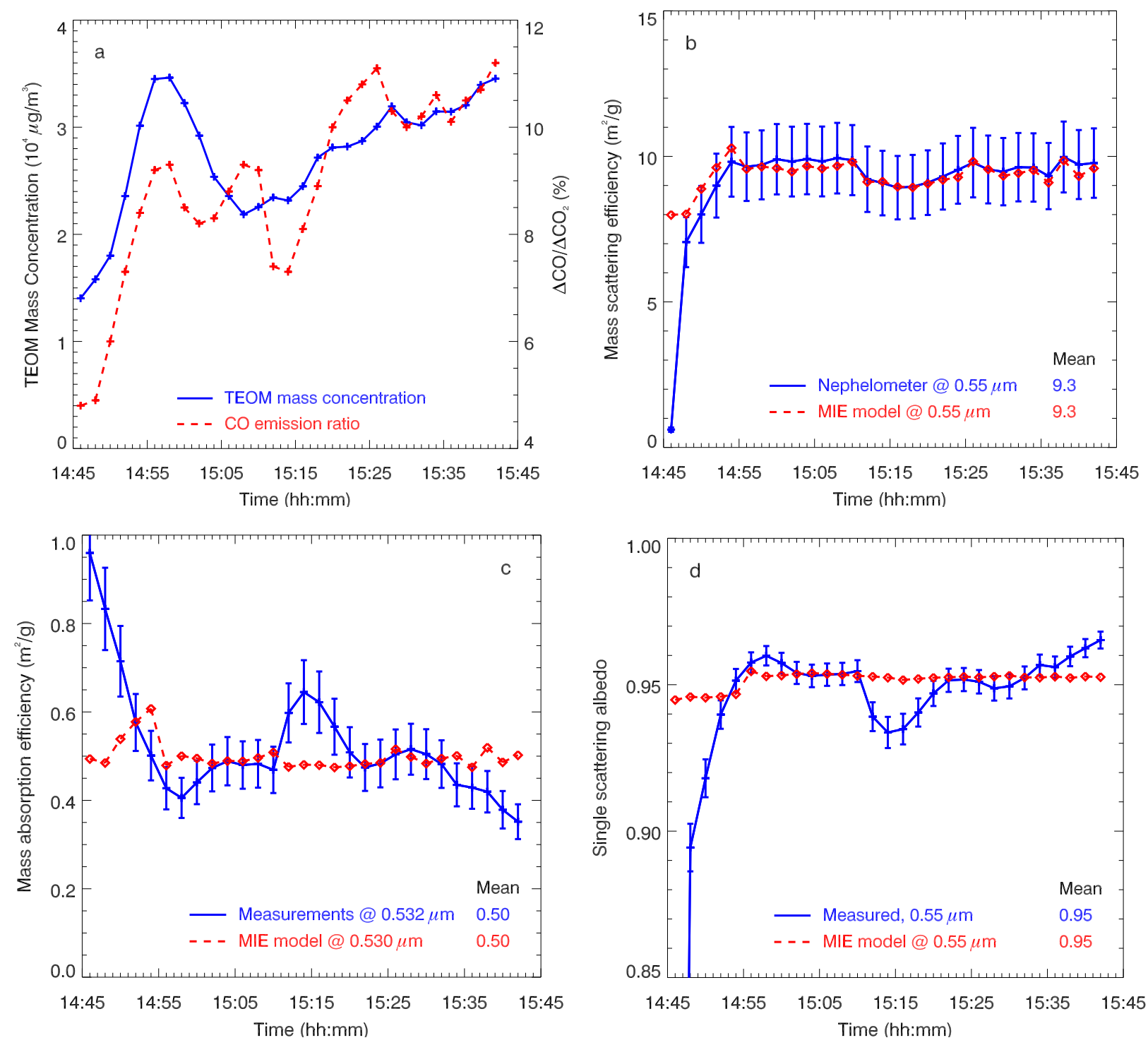

Fig. 4. Same as for Fig. 3, but for the combustion of musasa (MUSA23a).

were below 1.1 (MUSA23a) and smaller than 1.3 (SAVA20a) (Table 1). Because of these low growth factors we do not anticipate water to contribute significantly to the optical properties for the relative humidity encountered here $(\mathrm{RH}<10 \%)$.

The mean measured mass scattering efficiencies at $\lambda=0.55 \mu \mathrm{m}$ were $8.9 \pm 0.2 \mathrm{~m}^{2} \mathrm{~g}^{-1}$ and $9.3 \pm 0.3 \mathrm{~m}^{2} \mathrm{~g}^{-1}$, for the SAVA20a and MUSA23a experiments, respectively (Table 1). These averages (and standard deviations) were calculated from the 30 (SAVA20a) and 29 (MUSA23a) data points displayed in Figs. $3 \mathrm{~b}$ and $4 \mathrm{~b}$, respectively. Due to the single wavelength absorption measurements, the discussion here is restricted to a wavelength of $\lambda=0.55 \mu \mathrm{m}$. The mean mass absorption efficiencies at $\lambda=0.532 \mu \mathrm{m}$ were $0.51 \pm 0.02 \mathrm{~m}^{2} \mathrm{~g}^{-1}$ (SAVA20a) and $0.50 \pm 0.02 \mathrm{~m}^{2} \mathrm{~g}^{-1}$
(MUSA23a). For the single scattering albedo, mean values of $0.945 \pm 0.004$ (SAVA20a) and $0.950 \pm 0.020$ (MUSA23a) were obtained from the measurements (Table 1).

\subsection{Comparison with model calculations}

Figures 3 and 4 show the temporal development of the $\Delta \mathrm{CO} / \Delta \mathrm{CO}_{2}$ ratios (indicating the burning conditions), as well as the aerosol mass concentration and the optical properties during the combustion experiments SAVA20a and MUSA23a, respectively.

During the combustion of savanna grass, the $\Delta \mathrm{CO} / \Delta \mathrm{CO}_{2}$ values varied between 5 and $8 \%$ (Fig. 3a) with a temporal average of $6.4 \%$, showing that the flaming phase was dominating. The lowest $\mathrm{CO}$ emission ratio, and hence the 
Table 2. Effective refractive indices ( $\left.m_{\text {eff }}\right)$ and refractive indices for $\mathrm{BC}\left(m_{\mathrm{BC}}\right)$ and $\mathrm{OC}\left(m_{\mathrm{OC}}\right)$ which were retrieved for SAVA20a and MUSA23a using a mixture after Maxwell Garnett assuming different $\mathrm{BC}$ volume fractions $\left(\mathrm{VF}_{\mathrm{BC}}\right)$. The wavelength is $0.55 \mu \mathrm{m}$.

\begin{tabular}{lllll}
\hline Experiment & $\mathrm{m}_{\mathrm{eff}}$ & $\mathrm{VF}_{\mathrm{BC}}$ & $\mathrm{m}_{\mathrm{BC}}$ & $\mathrm{m}_{\mathrm{OC}}$ \\
\hline \multirow{3}{*}{$\mathrm{SAVA20a}$} & $1.60-0.010 i$ & 0.016 & $1.75-0.630 i$ & $1.60-0 i$ \\
& $1.60-0.010 i$ & 0.10 & $1.75-0.105 i$ & $1.58-0 i$ \\
& $1.60-0.010 i$ & 0.155 & $1.75-0.065 i$ & $1.57-0 i$ \\
MUSA23a & $1.56-0.010 i$ & 0.015 & $1.75-0.630 i$ & $1.56-0 i$ \\
& $1.56-0.010 i$ & 0.06 & $1.75-0.171 i$ & $1.55-0 i$ \\
& $1.56-0.010 i$ & 0.086 & $1.75-0.140 i$ & $1.54-0 i$ \\
\hline
\end{tabular}

most flaming combustion, was found at the beginning of the measurements at 11:29. At this time the highest mass specific absorption (Fig. 3c) and the lowest mass concentration (Fig. 3a), mass scattering (Fig. 3b) and single scattering albedo (Fig. 3d) were observed. Subsequently, the $\Delta \mathrm{CO} / \Delta \mathrm{CO}_{2}$ values increased and reached the least flaming combustion conditions at around 11:43. Likewise, the mass concentration as well as the mass scattering efficiency and the single scattering albedo increased until 11:43 as the combustion became less complete. At the same time the mass absorption efficiency decreased. After 11:43, the CO emission ratio decreased more or less continuously until the end of the combustion at 12:29 with a small local maximum around 12:23 which can be observed as a signature in the optical properties as well.

Also shown in Fig. 3 are the modelled optical properties (diamonds) for SAVA20a using a complex refractive index of $1.60-0.010 i(\lambda=0.55 \mu \mathrm{m})$ (Table 2) that was obtained by adjusting the complex refractive index of the model particles until the averaged calculated scattering and absorption coefficients agreed with the mean of the measurements (as described in Sect. 2.2). There is generally good agreement in the temporal development of the modelled and measured optical properties, especially for the mass scattering efficiency (Fig. 3b), where the mean percent difference (standard deviation) between model and measurements is $-1.3( \pm 1.1) \%$ and the calculated values are within the errors of the measurements during the whole period of the SAVA20a experiment. Similar good agreement is observed for the mass absorption efficiencies (Fig. 3c; mean percent difference: 1.4 $( \pm 4.0) \%)$ and the single scattering albedo (Fig. 3d; mean percent difference: $0.5( \pm 0.4) \%)$ except for the first $8 \mathrm{~min}$ and the last $5 \mathrm{~min}$ of the experiment where the flaming was strongest. During these two time periods the model underestimates the mass absorption by up to $50 \%$. On the other hand, for the time period when smouldering became most influential (around 11:45) the calculated mass absorption efficiency is approximately $45 \%$ higher than the corresponding measurements.
Similar results are found for the combustion of musasa (MUSA23a) presented in Fig. 4. The temporal development of the mass scattering efficiency is reproduced quite well by the model (Fig. 4b), whereas the calculated mass absorption efficiency significantly underestimates the measurements during the more flaming dominated phases at the beginning and in the middle of the experiment as can be seen in Fig. 4c. The mean percent difference between the calculated and measured optical properties is $-0.1( \pm 0.7) \%$, $-0.03( \pm 3.8) \%$ and $0.4( \pm 0.3) \%$ for the mass scattering efficiency, the mass absorption efficiency and the single scattering albedo, respectively. Here, the first scattering measurement was neglected, because it seems to be unrealistically low. The effective refractive index derived for the MUSA23a experiment was $1.56-0.010 i$ (Table 2).

\section{Discussion}

In this section the measured optical properties from the EFEU experiments SAVA20a and MUSA23a are compared to results from previous lab and field experiments. Possible reasons for differences are discussed and the measured optical properties are interpreted based on Mie calculations.

\subsection{Comparison of the optical properties with results from previous measurements}

Unless stated otherwise, the following brief summary of optical properties of biomass burning particles is taken from the review paper by Reid et al. (2005a) who evaluated numerous field and laboratory measurement campaigns. According to their analysis, typical (in-situ) mass scattering efficiencies in the mid-visible spectral range are between 2.8 and $4.2 \mathrm{~m}^{2} \mathrm{~g}^{-1}$ (mean: $3.6 \mathrm{~m}^{2} \mathrm{~g}^{-1}$ ) for fresh smoke in temperate, boreal and tropical forests as well as grassland fires. For particles from smouldering fires as well as aged smoke, the mass scattering efficiency is about $20 \%$ higher and ranges between 3.5 and $4.6 \mathrm{~m}^{2} \mathrm{~g}^{-1}$. Literature mass absorption efficiencies for green or white light from flaming conditions are typically in the 1.0 to $1.4 \mathrm{~m}^{2} \mathrm{~g}^{-1}$ range (mean: $1.2 \mathrm{~m}^{2} \mathrm{~g}^{-1}$ ), regardless of fuel type. For mixed phase and smouldering dominated combustion, black carbon emission is reduced, resulting in a lower mass absorption efficiency with values between 0.6$1.0 \mathrm{~m}^{2} \mathrm{~g}^{-1}$ and $0.2-0.7 \mathrm{~m}^{2} \mathrm{~g}^{-1}$, respectively. Consequently, mid-visible single scattering albedos increase from $0.65-$ 0.85 in the ignition/flaming phase to values of $0.8-0.9$ and $0.88-0.99$ for mixed phase and smouldering phase combustion, respectively.

Hence, the mass scattering efficiencies of $8.9 \mathrm{~m}^{2} \mathrm{~g}^{-1}$ and $9.3 \mathrm{~m}^{2} \mathrm{~g}^{-1}$ obtained for the SAVA20a and MUSA23a experiments are up to a factor 3 and 2.5 higher than mean literature values for flaming and smouldering burning conditions, respectively. The mass specific absorption efficiencies of $0.51 \mathrm{~m}^{2} \mathrm{~g}^{-1}$ (SAVA20a) and $0.50 \mathrm{~m}^{2} \mathrm{~g}^{-1}$ (MUSA23a) 
were by about a factor of 2.4 lower than typical mass absorption efficiencies obtained during flaming dominated fires, but agreed with literature data for mixed phase and smouldering combustions. The single scattering albedo obtained for SAVA20a (0.954) and MUSA23a (0.950) is also in a better agreement with literature data from mixed phase and smouldering dominated fires. These findings seem to contradict the measured mean $\mathrm{CO}$ emission ratios, which indicated more flaming burning conditions. This issue will be discussed below.

The actual particle shape might have an influence on the nephelometer measurements. Non-spherical particles scatter more strongly compared to ideal spheres, especially in the sideways directions, but this effect will increase the observed integrated scattering signal by no more than a few percent, if a particle ensemble is examined (Mugnai and Wiscombe, 1986). Hence, particle shape alone cannot explain the observed difference in mass scattering efficiency.

Mie calculations show that the high mass scattering efficiencies are mainly due to differences in particle size distribution. Compared to the Otavi fire much higher particle concentrations were obtained for the two EFEU experiments in the diameter range between $0.3 \mu \mathrm{m}$ and $1.0 \mu \mathrm{m}$ (Fig. 2), which according to Mie theory is the most efficient size range for light scattering. The higher concentration of large accumulation mode particles can be explained by enhanced coagulation inside the continuous flow mixing chamber due to the absence of natural plume dilution. Recalculating the optical properties for SAVA20a with the particle size distribution reported for the Otavi fire (Haywood et al., 2003) reduces the scattering coefficient by a factor of 1.7.

In addition, we cannot rule out that the high mass scattering efficiencies are at least partially due to negative biases in the TEOM mass due to evaporation of semi-volatile particle compounds. From the ratio of the TEOM-mass and the SMPS-APS-volume we obtain an effective particle density of 0.72 and $0.80 \mathrm{~g} \mathrm{~cm}^{-3}$ for SAVA20a and MUSA23a, respectively. This is considerably lower than typically reported effective densities for biomass burning aerosol $\left(1.35 \mathrm{~g} \mathrm{~cm}^{-3}\right.$, e.g. Rissler et al. (2006)). On the other hand, the mass emission factors of the two EFEU experiments were within the range of previously reported values and an underestimation of the mass concentration would also result in an overestimation of the mass absorption efficiency, which is in the range of typical literature values for mixed phase combustion fires.

The low EFEU mass absorption efficiencies are consistent with small $\mathrm{BC}$ fractions as suggested by the rather brown instead of black coloured impactor samples (Fig. 5). In addition, the larger absorption efficiencies given in the literature could be in part due to artefacts in absorption measurement, because commonly used filter based methods consistently overestimate absorption (Bond et al., 1999), whereas the photoacoustic spectrometer used during the EFEU experiments has shown to be accurate to within about $5 \%$, as supported by laboratory calibration experiments with var-

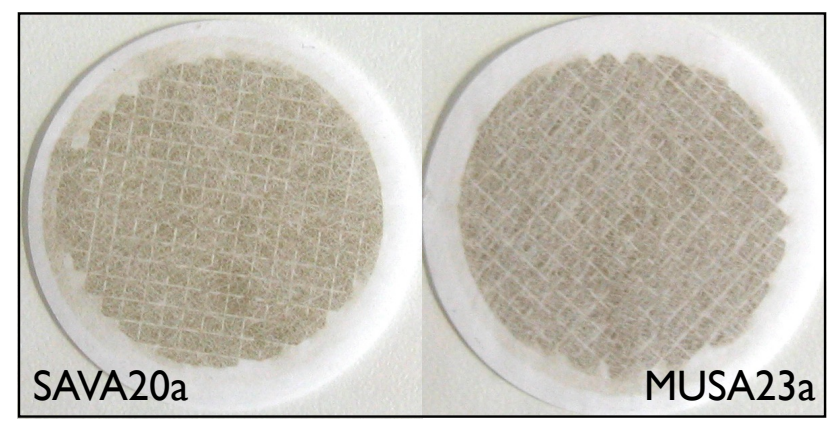

Fig. 5. Teflon filter samples from the savanna grass (left, SAVA20a) and the musasa (right, MUSA23a) combustion experiments.

ious types of aerosol, including biomass burning particles (Schnaiter et al., 2005).

There is also the possibility that the $\mathrm{CO}$ emission ratio is only a rough guide for the determination of the combustion phase, especially if aerosol properties are considered. According to the measured $\Delta \mathrm{CO} / \Delta \mathrm{CO}_{2}$ values, the EFEU experiments were performed under more flaming conditions. However, the video recording of the two combustion experiments clearly shows that mixed phase combustion (simultaneous occurrence of flaming and smouldering phase) occurred during extended periods of the combustion experiment. Since the aerosol emission factor is larger for smouldering combustion (Ferek et al., 1998), one would expect that for mixed phase combustion, the smouldering phase has a more pronounced impact on the average aerosol properties. This is consistent with our high scattering and low absorption efficiencies, which are characteristic for more smouldering optical aerosol properties in spite of the $\Delta \mathrm{CO} / \Delta \mathrm{CO}_{2}$ values pointing to flaming conditions.

Finally, compared to natural fires, the EFEU experiments were performed with dried fuel and the ventilation of the fire was enhanced, since air could access the small laboratory fire from all sides. This may have affected the burning conditions and subsequently the optical aerosol properties.

\subsection{Modelling of the optical properties and retrieved refrac- tive indices}

\subsubsection{Optical properties}

As described in Sect. 2.2, an effective refractive index of the particles was derived by iteratively adjusting the refractive index until average calculated mass scattering and absorption efficiencies best matched the measured ones. Hence, the good agreement between the averaged measured and calculated optical properties shown in Sect. 3.2 is not surprising. However, on the time-scale of each individual data point ( 2 min), differences may arise mainly due to variations in particles size and chemistry. Since the refractive index (and hence particle chemistry) was kept constant for each of the 
experiments, the excellent agreement between modelled and measured mass scattering efficiency indicates that the temporal variability in scattering can be explained by changes in the particle size distribution. On the other hand, changes in particle size do not fully explain the observed variation in absorption. At times when the $\Delta \mathrm{CO} / \Delta \mathrm{CO}_{2}$ value showed the highest and lowest values, i.e. when the chemical composition is expected to be most different from its mean value, the model is not able to reproduce the measured mass absorption efficiency. This suggests that, while changes in chemical composition due to varying burning conditions affect the mass absorption efficiency of biomass burning particles, the mass scattering efficiency is much less affected by changes in particle chemistry.

\subsubsection{Refractive indices}

For the EFEU experiments SAVA20a and MUSA23a effective refractive indices of $1.60-0.010 i$ and $1.56-0.010 i$ were obtained at $\lambda=0.55 \mu \mathrm{m}$ (Table 2). These refractive indices have real parts which are in the upper range of values reported in the literature, where values between 1.41 and 1.59 are given. However, since most of the literature values correspond to relative humidities that are larger than ours $(\mathrm{RH}<10 \%$; e.g. Guyon et al. (2003) refers to ambient conditions), at least some of them should be considered negatively biased compared to dry particle properties as reported here. While an effective refractive index of 1.41 at $\lambda=0.565 \mu \mathrm{m}$ was determined for fresh smoke in the Amazon region (Guyon et al., 2003), the highest real refractive indices between 1.56 and 1.59 were deduced for two biomass burning haze episodes during the Yosemite Aerosol Characterisation Study (McMeeking et al., 2005). Real parts between 1.53 and 1.58 were derived for smoke particles from laboratory combustion experiments with forest fuels (Carrico et al., 2004). Literature values for the imaginary part of the effective refractive index show a much larger variability with values between 0.0093 and 0.1 (Dubovik et al., 2002; Carrico et al., 2004; Colarco et al., 2004), and typically a smaller imaginary part was found for more smouldering combustion conditions. The values derived for the two EFEU experiments (0.010) are within the reported range, but tend to be at the lower end. This is especially worth mentioning, because the mean $\Delta \mathrm{CO} / \Delta \mathrm{CO}_{2}$ values of $6.4 \%$ (SAVA20a) and $9.0 \%$ (MUSA23a) suggest a flaming dominated combustion where large $\mathrm{BC}$ fractions and imaginary parts are expected.

As mentioned above, the refractive indices of the two model components, $\mathrm{OC}\left(\mathrm{m}_{\mathrm{OC}}\right)$ and $\mathrm{BC}\left(\mathrm{m}_{\mathrm{BC}}\right)$, were derived assuming an internal mixture of both components. Using the $\mathrm{EC}_{\mathrm{a}}$ mass fraction (SAVA20a: 15.5\%; MUSA23a: 8.6\%) determined with the thermographic method described in Sect. 2 as a proxy for the $\mathrm{BC}$ volume fraction. In this case, refractive indices of $\mathrm{m}_{\mathrm{BC}}=1.75-0.065 i$ and $\mathrm{m}_{\mathrm{OC}}=1.57-0 i$ were obtained using the Maxwell-Garnett mixing rule. In the case of MUSA23a, refractive indices of $\mathrm{m}_{\mathrm{BC}}=1.75-0.140 i$ and
$\mathrm{m}_{\mathrm{OC}}=1.54-0 i$ were determined (Table 2). In both cases, the imaginary parts of 0.065 and 0.140 for black carbon are very low, compared to the values between 0.1 and 1.0 given in the literature (Horvath, 1993). Assuming a stratified sphere model composed of a BC core and a concentric shell of organic material results in even lower $(\sim 20 \%)$ BC imaginary parts. This is because a stratified sphere absorbs more radiation than an internal mixture using the MaxwellGarnett effective medium approach (Bohren and Huffman, 1983), i.e. a lower imaginary part is sufficient for a stratified sphere. If on the other hand, black carbon is assumed to have a commonly used refractive index of $\mathrm{m}_{\mathrm{BC}}=1.75-0.630 i$ (Bond and Bergstrom, 2006), the average BC volume fraction has to be as low as $1.5 \%$ in order to achieve agreement between the measured and modelled optical properties (Table 2). Hence, there is an inconsistency between the relatively high fraction of apparent elemental carbon obtained with the thermographic method (8.6 to $15.5 \%$ ) and the low imaginary part of the refractive index of the aerosol particles. Thus, the question arises, if it could be possible that particles with a low fraction $(<5 \%)$ of strongly absorbing substances were emitted during the combustion of savanna grass and musasa, and if the thermal method inadvertently responds to high molecular weight organic substances, which would results in a positively biased $\mathrm{EC}_{\mathrm{a}}$ fraction.

For urban aerosol samples, the applied thermographic method yields $\mathrm{EC}_{\mathrm{a}}$ fractions within the range of variation of various methods, but it tends to overestimate the (actual) EC fraction due to e.g. charring of organic matter (see results for lab \#6/method VDI 2 in Schmid et al. (2001)). The reason for the observed inconsistency obtained for the biomass burning aerosol considered here is the fact that high molecular weight substances can be classified by this method as $\mathrm{EC}_{\mathrm{a}}$ instead of OC (Iinuma et al., 2007). Chemical analysis using capillary electrophoresis/electrospray ionization mass spectrometry (CE/ESI-MS) showed that the high molecular weight organic compounds that caused the high $\mathrm{EC}_{\mathrm{a}}$ fractions were probably lignin decomposition products emitted directly from the combustion source (Iinuma et al., 2007). Hence, it is possible that the determined apparent elemental carbon consists of the strongly absorbing black carbon as well as weakly absorbing organic matter (i.e. brown carbon). Application of the $\mathrm{EC}_{\mathrm{a}}$ fraction determined with the thermographic analysis would therefore result in an overestimation of the black carbon fraction and an underestimation of the OC fraction of the model particles.

The analysis of biomass burning aerosol sampled in Amazonia had already shown that a significant fraction of the aerosol mass was composed of high molecular weight organic material (Mayol-Bracero et al., 2002). It was concluded that humic-like substances (HULIS), which are used as a surrogate for brown carbon with respect to the optical properties (Andreae and Gelencsér, 2006), are generated in significant amounts during biomass burning. Hoffer et al. (2006) isolated humic-like substances from the fine biomass 
burning aerosol fraction collected during the SMOCC campaign in Brazil and derived a complex index of refraction at a wavelength of $0.532 \mu \mathrm{m}$ with real parts ranging between 1.65 and 1.68 and imaginary parts from 0.00163 up to 0.00187 . The emission of a significant fraction of lightabsorbing brown carbon was also observed during the initial period of coal combustion (Bond, 2001).

Hence, we conclude that the aerosol particles from the two EFEU experiments most likely contain only a small amount of strongly absorbing black carbon and instead a significant fraction of weakly absorbing brown carbon. Indeed, the filter samples for the experiments discussed here, were rather brown not black (Fig. 5). Since HULIS has a real refractive index of between 1.65 and 1.69 (Hoffer et al., 2006), this could explain the quite high real and the low imaginary parts of the refractive indices that were retrieved for SAVA20a and MUSA23a.

To confirm the hypothesis that the partially graphitized (brown) carbon has a large influence on the optical properties, wavelength dependent absorption measurements would have been instructive, because the absorption of brown carbon increases more sharply towards shorter wavelengths (Hoffer et al., 2006; Andreae and Gelencsér, 2006) than the absorption of black carbon (Bergstrom and Russell, 2002). Additionally, a better characterisation of the remaining unidentified organic fraction of the combustion aerosol could contribute to clarify this issue.

\section{Summary and conclusions}

As part of the 'Impact of Vegetation Fires on the Composition and Circulation of the Atmosphere' (EFEU) project, controlled combustion experiments were carried out to determine the physical, chemical and optical properties of fresh biomass burning aerosol as a function of the burning conditions. The measured mass scattering efficiencies for the combustion of savanna grass (SAVA20a) and musasa (MUSA23a) at a wavelength of $\lambda=0.55 \mu \mathrm{m}$ were $8.9 \pm 0.2 \mathrm{~m}^{2} \mathrm{~g}^{-1}$ and $9.3 \pm 0.3 \mathrm{~m}^{2} \mathrm{~g}^{-1}$, respectively. For the mass absorption efficiency, values of $0.51 \pm 0.02 \mathrm{~m}^{2} \mathrm{~g}^{-1}$ (SAVA20a) and $0.50 \pm 0.02 \mathrm{~m}^{2} \mathrm{~g}^{-1}$ (MUSA23a) were obtained. While the mass scattering efficiencies are up to a factor of 3 higher compared to literature data for similar burning conditions, the mass absorption efficiencies are lower than typically observed for flaming combustion, but agree well with literature data for mixed phase combustion. The higher concentration of particles between $0.3 \mu \mathrm{m}$ and $1.0 \mu \mathrm{m}$ diameter, which is the most effective size range for scattering, is the main reason for the high mass scattering efficiencies. The mass absorption efficiencies are consistent with the lower range of literature values for mixed phase and smouldering combustion.

The Mie calculations provided refractive indices of 1.60-0.010i (SAVA20a) and 1.56-0.010i (MUSA23a) $(\lambda=0.55 \mu \mathrm{m})$ indicating significantly lower imaginary parts than typically found in the literature for similar burning conditions. While the real parts of the refractive indices are in the upper range of typically reported values, the low imaginary parts are inconsistent with the high apparent elemental carbon fractions obtained from the thermographic analysis likely due to a positive bias of the thermal method, which is due to the fact that the thermal method responds to high molecular weight substances.

We suggest to conduct additional laboratory combustion experiments before the results reported here should be used in model investigations. For such experiments wavelength dependent absorption measurements and a better characterisation of the remaining undefined organic fraction would be instructive. Also, the combination of the thermal, optical, and solvent extraction methods is recommended in order to better characterise the fraction of the strong absorbing black carbon based on apparent elemental carbon measurements.

Acknowledgements. This work was funded by the Federal Ministry of Education and Research (BMBF), Germany within the AFO 2000 Program under Grant 07 ATF 46 (EFEU) and by the Max Planck Society. We thank M. Welling and all the other EFEU participants for their support during the EFEU campaigns. The authors are also grateful to P. Formenti (LISA) for their helpful comments.

Edited by: T. Kirchstetter

\section{References}

Anderson, T. L. and Ogren, J. A.: Determine aerosol radiative properties using the TSI 3563 integrating nephelometer, Aerosol Sci. Technol., 29, 57-69, 1998.

Andreae, M. O. and Gelencsér, A.: Black carbon or brown carbon? The nature of light absorbing carbonaceous aerosols, Atmos. Chem. Phys., 6, 3131-3148, 2006, http://www.atmos-chem-phys.net/6/3131/2006/.

Andreae, M. O. and Merlet, P.: Emission of trace gases and aerosols from biomass burning, Global Biogeochem. Cy., 14, 955-966, 2001.

Andreae, M. O., Atlas, E., Cachier, H., Cofer III, W. R., Harris, G., Helas, G., Koppmann, R., Lacaux, J., and Ward, D.: Trace gas and aerosol emissions from savanna fires, in: Biomass Burning and Global Change, edited by: Levine, J., MIT Press, Cambridge, Mass., 278-295, 1996.

Andreae, M. O.: Biomass Burning: Its History, Use, and Distribution and Its Impact on Environmental Quality and Global Climate, in: Global Biomass Burning: Atmospheric, Climatic, and Biospheric Implications, edited by: Levine, J., MIT Press, Cambridge, Mass., 3-21, 1991.

Bergstrom, R. W. and Russell, P. B.: Wavelength dependence of the absorption of black carbon particles: Predictions and results from the TARFOX experiment and implications for the aerosol single scattering albedo, J. Atmos. Sci., 59, 567-77, 2002.

Bohren, C. F. and Huffman, D. R.: Absorption and Scattering of Light by Small Particles, John Wiley \& Sons, Inc., 1983. 
Bond, T. C., Bergstrom, R. W., and Campbell, D.: Calibration and intercomparison of filter-based measurements of visible light absorption by aerosols, Aerosol Sci. Technol., 30, 582-600, 1999.

Bond, T. C.: Spectral dependence of visible light absorption by carbonaceous particles emitted from coal combustion, Geophys. Res. Lett., 28, 4075-4078, 2001.

Bond, T. C. and Bergstrom, R. W.: Light absorption by carbonaceous particles: An investigative review, Aerosol Sci. Technol., 40, 27-67, doi:10.1080/02786820500421521, 2006.

Carrico, C. M., Kreidenweis, S. M., Collett, Jr., J. L., Engling, G., and McMeeking, G. R.: Smoke Properties Derived from the Laboratory Combustion of Forest Fuels, Poster at the 23rd Annual AAAR Conference, Atlanta, Georgia, US, 2004.

Chakrabarty, R. K., Moosmüller, H., Garro, M. A., Arnott, W. P., Walker, J., Susott, R. A., Babbitt, R. E., Wold, C. E., Lincoln, E. N., and Hao, W. M.: Emissions from the laboratory combustion of wildland fuels: Particle morphology and size, J. Geophys. Res., 111, D07204, doi:10.1029/2005JD006659, 2006.

Chen, L.-W. A., Moosmüller, H., Arnott, W. P., Chow, J. C., and Watson, J. G.: Particle emissions from laboratory combustion of wildland fuels: In situ optical and mass measurements, Geophys. Res. Lett., 33, L04803, doi:10.1029/2005GL024838, 2006.

Christian, T., Kleiss, B., Yokelson, R., Holzinger, R., Crutzen, P., Hao, W., Saharjo, B., and Ward, D.: Comprehensive laboratory measurements of biomass-burning emissions: 1. Emissions from Indonesian, African, and other fuels, J. Geophys. Res., 108, 4719, doi:10.1029/2003JD003704, 2003.

Chýlek, P., Srivastava, V., Pinnick, R. G., and Wang, R.: Scattering of electromagnetic waves by composite spherical particles: Experiment and effective medium approximation, Appl. Opt., 27, 2396-2404, 1988.

Colarco, P. R., Schoeberl, M. R., Doddridge, B. G., Marufu, L. T., Torres, O., and Welton, E. J.: Transport of smoke from Canadian forest fires to the surface near Washington, D.C.: Injection height, entrainment, and optical properties, J. Geophys. Res., 109, D06203, doi:10.1029/2003JD004248, 2004.

Crutzen, P. J. and Andreae, M. O.: Biomass burning in the tropics: Impact on the atmospheric chemistry and biogeochemical cycles, Science, 250, 1669-1678, 1990.

Dubovik, O., Holben, B., Eck, T. F., Smirnov, A., Kaufman, Y. J., King, M. D., Tanré, D., and Slutsker, I.: Variability of absorption and optical properties of key aerosol types observed in worldwide locations, J. Atmos. Sci., 59, 590-608, 2002.

Ferek, R. J., Reid, J. S., Hobbs, P. V., Blake, D. R., and Liousse, C.: Emission factors of hydrocarbons, halocarbons, trace gases and particles from biomass burning in Brazil, J. Geophys. Res., 103, 32 107-32 118, 1998.

Guyon, P., Boucher, O., Graham, B., Becka, J., Mayol-Bracero, O. L., Roberts, G. C., Maenhaut, W., Artaxo, P., and Andreae, M. O.: Refractive index of aerosol particles over the Amazon tropical forest during LBA-EUSTACH 1999, J. Aerosol Sci., 34, 883-907, 2003.

Hao, W. M. and Liu, M.-H.: Spatial and temporal distribution of tropical biomass burning, Global Biogeochem. Cy., 8, 495-504, 1994.

Haywood, J., Osborne, S., Francis, P., Keil, A., Formenti, P., Andreae, M. O., and Kaye, P. H.: The mean physical and optical properties of regional haze dominated by biomass burning aerosol measured from the C-130 aircraft during SAFARI 2000,
J. Geophys. Res., 108, 8473, doi:10.1029/2002JD002226, 2003.

Hoffer, A., Gelencsér, A., Guyon, P., Kiss, G., Schmid, O., Frank, G., Artaxo, P., and Andreae, M. O.: Optical properties of humiclike substances (HULIS) in biomass-burning aerosols, Atmos. Chem. Phys., 6, 3563-3570, 2006,

http://www.atmos-chem-phys.net/6/3563/2006/.

Horvath, H.: Atmospheric light absorption - A review, Atmos. Environ., 27A, 293-317, 1993.

Iinuma, Y., Brüggemann, E., Gnauk, T., Andreae, M. O., Helas, G., Müller, K., Parmar, R., and Herrmann, H.: Source characterization of biomass burning particles: The combustion of selected European conifers, African hardwood, savannah grass, German peat and Indonesian peat, J. Geophys. Res., 112, D08209, doi: 10.1029/2006JD007120, 2007.

Kaufman, Y., Hobbs, P., Kirchhoff, V., Artaxo, P., Remer, L., Holben, B., King, M., Ward, D., Prins, E., Longo, K., Mattos, L. F., Nobre, C., Spinhirne, J., Ji, Q., Thompson, A., Gleason, J., Christopher, S., and Tsay, S.-C.: Smoke, Clouds, and RadiationBrazil (SCAR-B) experiment, J. Geophys. Res., 103, $31783-$ $31808,1998$.

Koppmann, R., von Czapiewski, K., and Reid, J. S.: A review of biomass burning emissions, Part I: Gaseous emissions of carbon monoxide, methane, volatile organic compounds, and nitrogen containing compounds, Atmos. Chem. Phys. Discuss., 5, 10455 10 516, 2005.

Lenoble, J.: The Particulate Matter from Biomass Burning: A Tutorial and Critical Review of Its Radiative Impact, in: Global Biomass Burning: Atmospheric, Climatic, and Biospheric Implications, edited by: Levine, J., MIT Press, Cambridge, Mass., 381-386, 1991.

Lindesay, J., Andreae, M. O., Goldammer, J., Harris, G., Annegarn, H., Garstang, M., Scholes, R., and van Wilgen, B. W.: International Geosphere Biosphere Programme/International Global Atmospheric Chemistry SAFARI-92 field experiment: Background and overview, J. Geophys. Res., 101, 23 521-23 530, 1996.

Massling, A., Wiedensohler, A., Busch, B., Neusüss, C., Quinn, P., Bates, T., and Covert, D.: Hygroscopic properties of different aerosol types over the Atlantic and Indian Oceans, Atmos. Chem. Phys., 3, 1377-1397, 2003,

http://www.atmos-chem-phys.net/3/1377/2003/.

Maxwell Garnett, J.: Colours in metal glasses and in metallic films, Philos. Trans. R. Soc. London, 203, 385-420, 1904.

Mayol-Bracero, O. L., Guyon, P., Graham, B., Roberts, G., Andreae, M. O., Decesari, S., Facchini, M., Fuzzi, S., and Artaxo, P.: Water-soluble organic compounds in biomass burning aerosols over Amazonia. 2. Apportionment of the chemical composition and importance of the polyacidic fraction, J. Geophys. Res., D20, 8091, doi:10.1029/2001JD000522, 2002.

McMeeking, G. R., Kreidenweis, S. M., Carrico, C. M., Collett, J. L., Day, D. E., and Malm, W. C.: Observations of smokeinfluenced aerosol during the Yosemite Aerosol Characterization Study: 2. Aerosol scattering and absorbing properties, J. Geophys. Res., 110, D18209, doi:10.1029/2005JD005907, 2005.

Mugnai, A. and Wiscombe, W. J.: Scattering from nonspherical Chebyshev particles. 1: Cross sections, single scattering albedo, asymmetry factor, and backscattered fraction, Appl. Opt., 25, 1235-1244, 1986.

Patterson, E. and McMahon, C.: Absorption characteristics of forest fire particulate matter, Atmos. Environ., 18, 2541-2551, 1984. 
Patterson, E., McMahon, C., and Ward, D.: Absorption properties and graphitic carbon emission factors of forest fire aerosols, Geophys. Res. Lett., 13, 129-132, 1986.

Penner, J., Dickinson, R., and O'Neill, C.: Effects of aerosol from biomass burning on the global radiation budget, Science, 256, 1432-1434, 1992.

Penner, J., Chuang, C., and Grant, K.: Climate forcing by carbonaceous and sulfate aerosols, Clim. Dynam., 14, 839-851, 1998.

Reid, J. S. and Hobbs, P. V.: Physical and optical properties of young smoke from individual biomass fires in Brazil, J. Geophys. Res., 103, 32 013-32 030, 1998.

Reid, J. S., Eck, T. F., Christopher, S. A., Koppmann, R., Dubovik, O., Eleuterio, D. P., Holben, B. N., Reid, E. A., and Zhang, J.: A review of biomass burning emissions, Part III: Intensive optical properties of biomass burning particles, Atmos. Chem. Phys., 5, 827-849, 2005a, http://www.atmos-chem-phys.net/5/827/2005/.

Reid, J. S., Koppmann, R., Eck, T. F., and Eleuterio, D. P.: A review of biomass burning emissions, Part II: Intensive physical properties of biomass burning particles, Atmos. Chem. Phys., 5, 799-825, 2005b, http://www.atmos-chem-phys.net/5/799/2005/.

Rissler, J., Vestin, A., Swietlicki, E., Fisch, G., Zhou, J., Artaxo, P., and Andreae, M. O.: Size distribution and hygroscopic properties of aerosol particles from dry-season biomass burning in Amazonia, Atmos. Chem. Phys., 6, 471-491, 2006, http://www.atmos-chem-phys.net/6/471/2006/.

Schmid, H., Laskus, L., Abraham, H. J., Baltensperger, U., Lavanchy, V., Bizjak, M., Burba, P., Cachier, H., Crow, D., Chow, J., Gnauk, T., Even, A., ten Brink, H. M., Giesen, K.-P., Hitzenberger, R., Hueglin, C., Maenhaut, W., Pio, C., Carvalho, A., Putaud, J.-P., Toom-Sauntry, D., and Puxbaum, H.: Results of the "carbon conference" international aerosol carbon round robin test stage I, Atmos. Environ., 35, 2111-2121, 2001

Schmid, O., Artaxo, P., Arnott, W., Chand, D., Gatti, L., Franck, G., Hoffer, A., Schnaiter, M., and Andreae, M. O.: Spectral light absorption by ambient aerosols influenced by biomass burning in the Amazon Basin. I: Comparison and field calibration of absorption measurement techniques, Atmos. Chem. Phys., 6, 34433462, 2006,

http://www.atmos-chem-phys.net/6/3443/2006/.
Schmid, O., Karg, E., Hagen, D. E., Whitefield, P. D., Ferron, G.: On the effective density of non-spherical particles as derived from combined measurements of aerodynamic and mobility equivalent size, J. Aerosol Sci., 38, 431-443, 2007.

Schnaiter, M., Schmid, O., Petzold, A., Fritzsche, L., Klein, K.F., Andreae, M. O., Helas, G., Thielmann, A., Gimmler, M., Moehler, O., Linke, C., and Schurath, U.: Measurement of wavelength.resolved light absorption by aerosol utilizing a UV-VIS extinction cell, Aerosol Sci. Technol., 39, 249-260, 2005.

Schneider, J., Weimer, S., Drewnick, F., Borrmann, S., Helas, G., Gwaze, P., Schmid, O., Andreae, M. O., and U. Kirchner, U.: Mass spectrometric analysis and aerodynamic properties of various types of combustion-related aerosol particles, Int. J. Mass. Spec., 258, 37-49, 2006.

Simoneit, B. R. T.: Biomass burning - a review of organic tracers for smoke from incomplete combustion, Appl. Geochem., 17, 129-162, 2002.

Swap, R., Annegarn, H., Suttles, J., Haywood, J., Helmlinger, M., Hely, C., Hobbs, P., Holben, B., Ji, J., King, M., Landmann, T., Maenhaut, W., Otter, L., Pak, B., Piketh, S., Platnick, S., Privette, J., Roy, D., Thompson, A., Ward, D., and Yokelson, R.: The Southern African Regional Science Initiative (SAFARI 2000): Overview of the dry season field campaign, S. Afr. J. Sci., 98, 125-130, 2002.

Wurzler, S., Herrmann, H., Neusüß, C., Stratmann, F., Wiedensohler, A., Wilck, M., Trautmann, T., Andreae, M. O., Helas, G., Trentmann, J., Langmann, B., Graf, H., and Textor, C.: Impact of vegetation fires on the composition and circulation of the atmosphere: Introduction of the research project EFEU, J. Aerosol Sci., 32, Suppl. 1, S199-S200, 2001. 